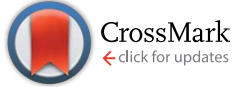

Cite this: RSC Adv., 2016, 6, 67232

\title{
Evaluation of the efficacy of carbon nanotubes for delivering peptides into mitochondria $\uparrow$
}

\author{
Graziella Ficociello, ${ }^{a}$ Adele Salemme, ${ }^{b}$ Daniela Uccelletti, ${ }^{a}$ Silvana Fiorito, ${ }^{c}$ \\ Anna Rita Togna, ${ }^{b}$ Lorenzo Vallan, ${ }^{d}$ Jose M. González-Domínguez, ${ }^{d}$ Tatiana Da Ros, ${ }^{d}$ \\ Silvia Francisci ${ }^{a}$ and Arianna Montanari ${ }^{\star a e}$
}

\begin{abstract}
Mitochondrial ( $\mathrm{mt}$ ) diseases are devastating neurodegenerative pathologies due to mutations in nuclear or $\mathrm{mt}$ genes. Among mtDNA pathogenic mutations, more than one half have been identified in transfer RNA (tRNA) genes. These are responsible for a wide range of pathologies including myopathies, encephalopathies, cardiomyopathies and deafness for which no effective treatment is available at present. Therefore, new strategies to suppress their damaging effects are required to envisage therapeutic approaches for these diseases. Here we report data for carbon nanotube (CNT) derivatives showing that the conjugates bearing a specific peptide sequence are able to target the mitochondria in yeast and human monocyte cells while the control derivative without the peptide diffuses into the cytoplasm. Moreover the compounds do not affect cellular viability and cytotoxicity both in vitro and in vivo. Toxicity of the constructs is also assessed on the simple pluricellular model Caenorhabditis elegans.
\end{abstract}

Received 1st June 2016 Accepted 6th July 2016

DOI: $10.1039 / c 6 r a 14254 k$

www.rsc.org/advances phenotype of strains carrying human equivalent point mutations in the cognate mt tRNAs. ${ }^{1}$

The results obtained in the yeast model have been paralleled in human cell lines, ${ }^{6-9}$ and we demonstrated that human $\mathrm{mt}$ LeuRS-Cterm is the region necessary and sufficient to suppress the mt defects of mutants in both cognate and non-cognate $\mathrm{mt}$ tRNAs (namely tRNA ${ }^{\text {Leu(UUR) }}$, tRNA ${ }^{\text {Ile }}$, tRNA ${ }^{\text {Val }}$, all of which are aminoacylated by class Ia aaRSs) with higher rescuing activity than the whole mt LeuRS. ${ }^{\mathbf{1 0 , 1 1}}$

Moreover we have previously demonstrated that the yeast mt LeuRS-Cterm was endowed with mt targeting activity. ${ }^{5}$ We have also identified the minimal sequences of the mt LeuRS-Cterm responsible for suppression. The short isolated peptides of 15 and 16 amino acids (named $\beta 30 \_31$ and $\beta 32 \_33$ ) were endowed with the same suppressing activity of the full Cterm when overexpressed in a broad range of different yeast mt tRNA mutants., ${ }^{5,12}$ In vitro experiments demonstrated that mt LeuRSCterm peptide was able to directly and specifically interact either with human cognate mt tRNA ${ }^{\text {Leu(UUR) }}$ either with noncognate mt tRNA ${ }^{\text {Ile }}$ even if with 4 -fold lower affinity. ${ }^{\mathbf{1 1}}$ Moreover we have shown that the $330 \_31$ peptide specifically interacts with cognate and non-cognate mt tRNAs. ${ }^{5,13}$ The demonstration that the catalytic function of $\mathrm{mt}$ LeuRS is not required for rescuing activity and that the interaction occurring between the mt LeuRS-Cterm domain and the cognate or non-cognate tRNA in in vitro shift binding experiment ${ }^{5}$ strongly point to a 'chaperone-like' molecular effect. We hypothesized that the interaction of the overexpressed sequences with the mutated mt tRNA stabilizes the native-like tRNA structure which would better establish interactions with other macromolecular partners 
required for mt protein synthesis, and/or arises less susceptible to degradation events.

In recent years the mt targeting has been proposed as a new therapeutic approach for $\mathrm{mt}$ dysfunction-related diseases. At present highly active compounds have been identified; however, the enormous challenge that should be overcome is mainly due to the difficult road that these molecules have to take for $\mathrm{mt}$ entrance from the cellular surface. This way is further complicated because the extremely complex nature of the mitochondria themselves.

Over the last decade, nanotechnology has been extensively introduced into biomedical applications, including biological detection, drug delivery, diagnostic imaging, and tissue engineering. ${ }^{14}$ Nanotechnology based delivery vehicles provide numerous advantages to increase the therapeutic activities of small molecules. ${ }^{15}$

CNTs are a very promising nanomaterial and there are many studies on their possible application as scaffold for tissue regeneration, biosensors and drug vectors. ${ }^{16,17}$ The characteristics that render them so interesting are ranging from their peculiar one dimension structure to their electronic properties. From the structural point of view, CNTs can present one or many concentric walls (single and multi-walled CNTs, SWCNTs and MWCNTs, respectively), and they can vary in diameter, chirality and length. Their tendency to aggregate can be overcome by chemical functionalization, which can be non covalent or covalent. These two approaches result in different pros and cons, in fact while in the first case the electronic characteristics of CNTs are preserved without the disruption of the aromatic system, the second approach changes the hybridization of the carbon atoms from $\mathrm{sp}^{2}$ to $\mathrm{sp}^{3}$. However, the covalent derivatization leads to more stable systems in which the introduced functionalizations cannot be easily detached from the surface. Another difference that plays an important role in the biological application of CNTs is due to the different internalization mechanism depending on the functionalization pattern. CNTs in fact are able to enter the cells both via an energy-dependent, endosomally mediated internalization mechanism ${ }^{\mathbf{1 8}}$ and via direct translocation through the plasma membrane into the cytoplasm. ${ }^{19,20}$ Between the two possible pathways of internalization, the nature of the functionalization of nanotubes seems to be of great importance. Indeed, the presence of biomacromolecules such as proteins, antibodies, DNA or phospholipidic structures supramolecularly linked on the nanotube surface has been associated with energy-dependent endocytotic uptake. ${ }^{18}$ It means that, the direct conjugation of short peptides on the CNTs surface could allow the direct internalization of the system, escaping the endosomal pathway and surviving the lisosomal destiny. The potential benefits of integrating nanomaterials based on carbon nanotubes have been recently engineered to target mitochondria..$^{\mathbf{2 1 , 2 2}}$

Here we test the mt delivery activity of MWCNTs conjugated with the short peptide of 16 amino acids ( $\beta 32 \_33$ ) derived from the Cterm of human mt LeuRS. Fluorescence microscopy shows mt localization in yeast and human monocyte cells for these constructs, while the control without the peptide $\beta 32 \_33$ is diffused in the cytoplasm; when the peptide is conjugated the mt targeting activity is improved at least in monocyte cells. Moreover, Caenorhabditis elegans lifespan and fertility are not affected by CNTs treatments.

\section{Experimental}

\section{Synthesis of CNTs}

The peptides with and without FITC have been purchased from CRIBI (Centro di Biotecnologie - University of Padova). In the suppressive sequence, a cysteine residue at the $\mathrm{N}$-terminus has been introduced to allow the so-called thiol-Michael addition click reaction on the nanotubes, properly bearing maleimide units. Analogously a lysine-FITC residue was added at the C-terminus, to introduce a fluorescent dye on the peptides itself. So the used peptides are: CKKSFLSPRTALINFLVK(FITC)$\mathrm{OH}$ and CKKSFLSPRTALINFLV-OH.

\section{Materials and reagents}

Pristine multi-walled carbon nanotubes (p-MWCNTs) were acquired from Nanostructured \& Amorphous Materials (Lot. \#1237YJ). According to the manufacturer, the p-MWCNTs had a purity of $>95 \%, 20-30 \mathrm{~nm}$ external diameter, internal diameter 5-10 nm, 0.5-2 $\mu \mathrm{m}$ length, specific surface area of $110-130 \mathrm{~m}^{2}$ $\mathrm{g}^{-1}$ and density of $\sim 2.1 \mathrm{~g} \mathrm{~cm}^{-3}$. All other reagents were purchased from Sigma Aldrich, TCI, Fluorochem or Carlo Erba and were used without further treatments. Membrane filters were $47 \mathrm{~mm}$ diameter/0.45 $\mu \mathrm{m}$ pore size hydrophilic PTFE sheets from Merck-Millipore commercial source (Omnipore ${ }^{\circledR}$ JHWP04700). In order to perform the Kaiser test, a commercial kit containing the necessary solutions was employed (Sigma Aldrich 60017-1EA).

\section{Characterization techniques}

Thermogravimetric analyses (TGA) were recorded on a TGA Q500 (TA instruments) under a flow of $\mathrm{N}_{2}\left(90 \mathrm{~mL} \mathrm{~min}^{-1}\right)$ following a temperature program with an isothermal at $100{ }^{\circ} \mathrm{C}$ for $20 \mathrm{~min}$, followed by a ramp of $10{ }^{\circ} \mathrm{C} \mathrm{min}^{-1}$ to $700{ }^{\circ} \mathrm{C}$. The samples ranged from 1 to $2 \mathrm{mg}$, precisely weighed. TGA analyses and derivatives of all compounds are shown in Fig. S1. $\dagger$ Fluorescence measurements were performed on a Cary Eclipse (Agilent Technologies) fluorescence spectrophotometer using quartz cuvettes with a path length of $1 \mathrm{~cm}$. Kaiser test was applied to functionalized MWCNTs through the experimental procedure reported elsewhere. ${ }^{23}$ The UV/Vis-NIR spectroscopic measurements implied in this analysis were carried out on a Varian Cary 5000 spectrophotometer using polystyrene cuvettes with a path length of $1 \mathrm{~cm}$. Syntheses of amino acids 1 (ref. 24) and 2 (ref. 25) were performed as already reported in literature.

\section{Functionalization of MWCNTs}

f-MWCNT 1. $90 \mathrm{mg}$ of p-MWCNTs (1 eq., $7.5 \mathrm{mmol} \mathrm{C}$ ) in 90 $\mathrm{mL}$ of $o$-dichlorobenzene through bath sonication for $10 \mathrm{~min}$. The suspension was brought to $180{ }^{\circ} \mathrm{C}$ under constant magnetic stirring and then $180 \mathrm{mg}$ of the $N$-Phth $\alpha$-amino acid $1(0.072$ eq., $0.54 \mathrm{mmol}$ ) and $80 \mathrm{mg}$ of paraformaldehyde (0.35 eq., 2.6 
$\mathrm{mmol}$ ). The reaction mixture was left stirring at $180{ }^{\circ} \mathrm{C}$ for $2 \mathrm{~h}$, then it was cooled down to room temperature and another 180 $\mathrm{mg}$ of 1 and $80 \mathrm{mg}$ of paraformaldehyde were added, while applying $5 \mathrm{~min}$ of bath sonication. This systematic was repeated up to a total of five times, every two hours. Afterwards, the reaction medium was left at $180{ }^{\circ} \mathrm{C}$ under magnetic stirring until completion of $24 \mathrm{~h}$ from the start. The medium was again cooled down to room temperature and vacuum-filtered over Omnipore ${ }^{\circledR}$ membrane and copiously washed with $N, N^{\prime}$-dimethylformamide (DMF). The solid cake was re-dispersed in DMF by aid of bath sonication, and the filtration process was repeated enough times to eventually obtain a colourless filtrate. Then, the same filtration was repeated a couple of times with $\mathrm{MeOH}$ and finally rinsed with diethyl ether and dried under vacuum. Obtained mass: $93 \mathrm{mg}$. Functionalization degree: 372 $\mu \mathrm{mol} \mathrm{g}{ }^{-1}$ (TGA); $150 \mu \mathrm{mol} \mathrm{g}^{-1}$ (Kaiser test after deprotection).

$\boldsymbol{f}$-MWCNT $2.90 \mathrm{mg}$ of $\boldsymbol{f}$-MWCNT 1 ( 1 eq., $\sim 7.5 \mathrm{mmol} \mathrm{C}$ ) were dispersed in $90 \mathrm{~mL}$ of DMF with bath sonication for $10 \mathrm{~min}$. The suspension was brought to $120{ }^{\circ} \mathrm{C}$ under constant magnetic stirring and then $180 \mathrm{mg}$ of the $N$-Boc $\alpha$-amino acid 2 ( 0.079 eq., $0.59 \mathrm{mmol}$ ) and $80 \mathrm{mg}$ of paraformaldehyde (0.35 eq., 2.6 $\mathrm{mmol}$ ). The reaction mixture was left stirring at $120^{\circ} \mathrm{C}$ for $2 \mathrm{~h}$, then it was cooled down to room temperature and another 180 $\mathrm{mg}$ of 2 and $80 \mathrm{mg}$ of paraformaldehyde were added, while applying $5 \mathrm{~min}$ of bath sonication. This systematic was repeated up to a total of five times, every two hours. Afterwards, the reaction medium was left at $120{ }^{\circ} \mathrm{C}$ under magnetic stirring until completion of $24 \mathrm{~h}$ from the start. The medium was again cooled down to room temperature and vacuum-filtered over Omnipore ${ }^{\circledR}$ membrane and copiously washed with DMF. The solid cake was re-dispersed in DMF by aid of bath sonication, and the filtration process was repeated enough times to eventually obtain a colourless filtrate. Then, the same filtration was repeated a couple of times with $\mathrm{MeOH}$ and finally rinsed with diethyl ether and dried under vacuum. Obtained mass: $88 \mathrm{mg}$. Functionalization degree: $25 \mu \mathrm{mol} \mathrm{g}{ }^{-1}$ (TGA); $37 \mu \mathrm{mol} \mathrm{g} \mathrm{g}^{-1}$ (Kaiser test after selective deprotection of the Boc protecting group).

$\boldsymbol{f}$-MWCNT 3. $80 \mathrm{mg}$ of $\boldsymbol{f}$-MWCNT 2 were dispersed in a hydrazine monohydrate solution of $65 \%$ in ethanol $(1 \mathrm{~mL}$ in $80 \mathrm{~mL}$ EtOH). The medium was kept under stirring for $24 \mathrm{~h}$ at room temperature. The obtained product was vacuum-filtered and washed with Milli-Q water until the falling waters presented neutral $\mathrm{pH}$. To favour the removal of hydrazine leftovers, while keeping the Boc group unharmed, the first aliquot of washing water was slightly acidified with one droplet of $\mathrm{HCl} 4$ $\mathrm{M}$. The solid cake over the filter was rinsed with $\mathrm{MeOH}$ and $\mathrm{Et}_{2} \mathrm{O}$ and was left to dry under vacuum. Obtained mass: $77 \mathrm{mg}$. Functionalization degree: $360 \mu \mathrm{mol} \mathrm{g}^{-1}$ (free amine from TGA); $105 \mu \mathrm{mol} \mathrm{g}^{-1}$ (Kaiser test).

$\boldsymbol{f}$-MWCNT 6. $30 \mathrm{mg}$ of $\boldsymbol{f}$-MWCNT 3 (3 $\mu \mathrm{mol}$ of free amine groups, according to Kaiser test) were dispersed in $30 \mathrm{~mL}$ of anhydrous DMF and the mixture was bath-sonicated for $20 \mathrm{~min}$, while keeping an argon balloon connected. Then $80 \mathrm{mg}$ of $\mathrm{N}$ succinimidyl-3-maleimidopropionate (100 eq., $0.30 \mathrm{mmol}$ ) and $0.17 \mathrm{~mL}$ TEA (400 eq., $1.2 \mathrm{mmol}$ ) were added. The reaction underwent at room temperature for $36 \mathrm{~h}$ under static argon atmosphere. The medium was then filtered, washed with DMF, $\mathrm{MeOH}$ and $\mathrm{Et}_{2} \mathrm{O}$, and finally dried under vacuum. Obtained mass: $26 \mathrm{mg}$. Functionalization degree: $57 \mu \mathrm{mol} \mathrm{g}^{-1}$ (TGA); 66 $\mu \mathrm{mol} \mathrm{g}^{-1}$ (Kaiser test, as a difference between $\boldsymbol{f}$-MWCNT 6 and f-MWCNT 3).

f-MWCNT 7. $24 \mathrm{mg}$ of $\boldsymbol{f}$-MWCNT 6 were bath-sonicated for 10 min in $25 \mathrm{~mL}$ of an aqueous solution of $\mathrm{HCl}(4 \mathrm{M})$. The mixture was left stirring overnight at room temperature and subsequently filtered and rinsed with Milli-Q water until detecting neutral $\mathrm{pH}$ in the eluate. The solid cake over the filter membrane was rinsed with $\mathrm{MeOH}$ and $\mathrm{Et}_{2} \mathrm{O}$ and dried in vacuum. Obtained mass: $23 \mathrm{mg}$. Functionalization degree: 190 $\mu \mathrm{mol} \mathrm{g}{ }^{-1}$ (free amine from TGA); $56 \mu \mathrm{mol} \mathrm{g}{ }^{-1}$ (Kaiser test).

$\boldsymbol{f}$-MWCNT $8.10 \mathrm{mg}$ of $\boldsymbol{f}$-MWCNT $7(0.15 \mu \mathrm{mol}$ of maleimide groups, estimated from Kaiser test) were dispersed in $10 \mathrm{~mL}$ of DMF, by bath sonication for 20 min while an argon balloon was connected to the system. Afterwards, $5 \mathrm{mg}$ of the fluorophorelabelled peptide CKKSFLSPRTALINFLVK(FAM) (13.7 eq., 2.06 $\mu \mathrm{mol})$ were added and the medium was allowed to react at room temperature for 2 days with constant magnetic stirring. The mixture was filtered and washed with DMF, Milli-Q water, $\mathrm{MeOH}, \mathrm{Et}_{2} \mathrm{O}$, and finally dried under vacuum. All filtrands were controlled by fluorescence spectroscopy in order to assure the absence of fluorescein. Obtained mass: $10 \mathrm{mg}$. Functionalization degree: $35 \mu \mathrm{mol} \mathrm{g}^{-1}$ (TGA).

$\boldsymbol{f}$-MWCNT 9. $10 \mathrm{mg}$ of $\boldsymbol{f}$-MWCNT $7(0.15 \mu \mathrm{mol}$ of maleimide groups, estimated from Kaiser test) were dispersed in $10 \mathrm{~mL}$ of DMF, by bath sonication for 20 min while an argon balloon was connected to the system. Afterwards, $4.2 \mathrm{mg}$ of the peptide CKKSFLSPRTALINFLVK (13.7 eq., $2.06 \mu \mathrm{mol})$ were added and the medium was allowed to react at room temperature for 2 days with constant magnetic stirring. The mixture was filtered and washed with DMF, Milli-Q water, $\mathrm{MeOH}, \mathrm{Et}_{2} \mathrm{O}$, and finally dried under vacuum. All filtrands were controlled by fluorescence spectroscopy in order to assure the absence of fluorescein. Obtained mass: $9 \mathrm{mg}$. Functionalization degree: $34 \mu \mathrm{mol} \mathrm{g}^{-1}$ (TGA).

$\boldsymbol{f}$-MWCNT 10. $9 \mathrm{mg}$ of $\boldsymbol{f}$-MWCNT $9(0.46 \mu \mathrm{mol}$ of free amine groups, estimated from Kaiser test) were dispersed in $9 \mathrm{~mL}$ of anhydrous DMF through bath sonication for $20 \mathrm{~min}$ while keeping an argon balloon connected. Afterwards, $90 \mathrm{mg}$ of fluorescein isothiocyanate (FITC, 500 eq., $0.23 \mathrm{mmol}$ ) and $69 \mu \mathrm{L}$ TEA (1087 eq., $0.50 \mathrm{mmol}$ ) were added. The mixture was stirred at room temperature for two days, and then vacuum-filtered. The washing sequence was again DMF, MeOH, Milli-Q water and $\mathrm{Et}_{2} \mathrm{O}$, and the product was finally dried under vacuum. The washing at each solvent was repeated as much as necessary until observation of no FITC fluorescent bands in the eluent. Obtained mass: $6 \mathrm{mg}$.

f-MWCNT 4. $15 \mathrm{mg}$ of $\boldsymbol{f}$-MWCNT 3 were bath-sonicated for 10 min in $15 \mathrm{~mL}$ of an aqueous solution of $\mathrm{HCl}(4 \mathrm{M})$. The mixture was left stirring overnight at room temperature and subsequently filtered and rinsed with Milli-Q water until detecting neutral $\mathrm{pH}$ in the filtrand. The solid cake over the filter membrane was rinsed with $\mathrm{MeOH}$ and $\mathrm{Et}_{2} \mathrm{O}$ and dried in vacuum. Obtained mass: $14 \mathrm{mg}$. Functionalization degree: 50 $\mu \mathrm{mol} \mathrm{g}^{-1}$ (Kaiser test as a difference between $\boldsymbol{f}$-MWCNT 4 and f-MWCNT 3). 
$\boldsymbol{f}$-MWCNT 5. $13 \mathrm{mg}$ of $\boldsymbol{f}$-MWCNT $4(0.65 \mu \mathrm{mol}$ of free amine groups, estimated from Kaiser test) were dispersed in $7 \mathrm{~mL}$ of anhydrous DMF through bath sonication for $20 \mathrm{~min}$ while keeping an argon balloon connected. Afterwards, $25 \mathrm{mg}$ of FITC (100 eq., $65 \mu \mathrm{mol})$ and $16 \mu \mathrm{L} \mathrm{TEA} \mathrm{(115} \mathrm{eq.,} 98 \mu \mathrm{mol})$ were added. The mixture was stirred at room temperature for two days, and then vacuum-filtered. The washing sequence was again DMF, Milli-Q water, $\mathrm{MeOH}$, and $\mathrm{Et}_{2} \mathrm{O}$, and the product was finally dried under vacuum. The washing at each solvent was repeated as much as necessary until observation of no FITC fluorescent bands in the filtrand. Obtained mass: $4 \mathrm{mg}$. Functionalization degree: $90 \mu \mathrm{mol} \mathrm{g}^{-1}$ (TGA); $20 \mu \mathrm{mol} \mathrm{g}^{-1}$ (Kaiser test).

The fluorescence measurements of $\boldsymbol{f}$-MWCNT 5, $\boldsymbol{f}$-MWCNT 8, $f$-MWCNT 10 in water are shown in Fig. S2. $\dagger$

For the experiments the $f$-MWCNT 5, $f$-MWCNT 8 and $\boldsymbol{f}$-MWCNT 10 preparations were re-suspended in phosphate buffered saline PBS (137 mM NaCl, $2.7 \mathrm{mM} \mathrm{KCl,} 10 \mathrm{mM}$ $\mathrm{Na}_{2} \mathrm{HPO}_{4}, 2 \mathrm{mM} \mathrm{KH} \mathrm{PO}_{4}$ ) to have $1 \mathrm{mg} \mathrm{mL}^{-1}$ of concentration. Before using they were bath-sonicated for $2 \mathrm{~h}$.

\section{Yeast experiments}

Saccharomyces cerevisiae wild type (WT) strain used in these studies was the W303-1A (MAT a, ade2-1, can1-100, his3-11,15, leu2-3,112, trp1-1, ura3-1) rho $^{+} .^{26}$ Cells were grown in YP complete medium (1\% yeast extract and $1 \%$ peptone from Difco) containing $2 \%$ glucose. Viability and toxicity was measured calculating the growth capability of a diluted fresh culture $\left(10^{6}\right.$ cells per $\left.\mathrm{mL}\right)$ treated or not with MWCNTs. We tested 10, 20, 40, 80, 100 and $150 \mu \mathrm{g} \mathrm{mL}^{-1}$ from $2 \mathrm{~h}$ up to $72 \mathrm{~h}$. The fluorescent signal was maintained into the cells up to 8 days of treatment; moreover the cells were viable and they presented buds. To visualize mitochondria, the cells were incubated with $0.5 \mu \mathrm{M}$ MitoTracker Red FM (Life Technologies Italy) for $15 \mathrm{~min}$ at room temperature or fixed with $1 \%$ formaldehyde for $30 \mathrm{~min}$ at room temperature and treated with $1 \mu \mathrm{g}$ $\mathrm{mL}^{-1}$ of DAPI (Sigma-Aldrich). One aliquot of the cells was fixed on glass slide and the fluorescent signal was observed by Zeiss Axio Imager Z1 Fluorescence Microscope (supported by AxioVision 4.8 Digital Image Processing System and objective lens $63 \times$ oil).

\section{Human monocyte experiments}

Human peripheral blood mononuclear cell cultures were prepared as follow: fresh EDTA-treated buffy coats from the blood of healthy donors were provided by the Transfusion Center at the Sapienza University of Rome in accordance with the Helsinki Declaration of 1975 and 1983. Monocytes were obtained from peripheral blood mononuclear cells (PBMCs). PBMCs were isolated by centrifugation on a Lymphoprep ${ }^{\mathrm{TM}}$ density gradient. The mononuclear cells were washed twice with $\mathrm{Mg}^{2+} / \mathrm{Ca}^{2+}$-free-phosphate-buffered solution by re-suspension and centrifugation at $300 \mathrm{~g}$ at room temperature. Cells were subsequently tested for their viability by trypan blue exclusion and re-suspended in Roswell Park Memorial Institute (RPMI)1640 medium, supplemented with $10 \%$ heat-inactivated fetal bovine serum, $2 \mathrm{mM}$ glutamine, penicillin $\left(100 \mathrm{U} \mathrm{mL}^{-1}\right)$ and streptomycin (100 $\mathrm{mg} \mathrm{mL}^{-1}$ ). Mononuclear cells were plated in wells of tissue culture plates, and monocytes were obtained by selective adherence (120 $\left.\mathrm{min}, 37{ }^{\circ} \mathrm{C}, 5 \% \mathrm{CO}_{2}\right)$. Non-adherent cells were removed and discarded, while the adherent cells were washed carefully twice with pre-warmed medium. Complete medium was then added to the plates, and the cells were cultured for $24 \mathrm{~h}$ before treatments.

For assessing the intracellular localization of the MWCNT constructs, fluorescence microscopy observation was assessed. Monocytes were plated on coverslips $\left(1 \times 10^{6}\right.$ cells per coverslip), inside a Petri dish filled with supplemented RPMI-1640 medium and treated with $f$-MWCNT 5, $\boldsymbol{f}$-MWCNT 8, and $f$-MWCNT 10 at $100 \mu \mathrm{g} \mathrm{mL}{ }^{-1}$ for $24 \mathrm{~h}, 48 \mathrm{~h}$ and $120 \mathrm{~h}$. The medium was removed and the cells washed with fresh and prewarmed PBS. The intracellular localization of MWCNTs was traced incubating the cells with the mitochondrial marker MitoTracker Red FM (Life Technologies Italy) at concentration of $10 \mathrm{nM}$, in growth medium without serum, at $37^{\circ} \mathrm{C}$ for $30 \mathrm{~min}$. The monocytes were then washed with pre-warmed PBS and fixed in $4 \%$ paraformaldehyde diluted in PBS, for $10 \mathrm{~min}$ at room temperature. After washing several times in buffer the cells were examined using an Axioskop 2 Plus Microscope (supported by ZEN 2012 (blue edition) Imaging Software and objective lens $40 \times$ ).

Monocyte viability was assessed by 3-(4,5-dimethylthiazol2-yl)-2,5-diphenyltetrazolium bromide (MTT) from Sigma Chemicals Co. (St. Louis, MO, USA) whereas for cytotoxicity assay we used the LDH detection kit (lactate dehydrogenase assay) was from Roche (Roche Diagnostics, Indianapolis, IN, USA). In MTT assay, mt dehydrogenase enzyme of living cells converts yellow MTT to purple formazan, which is spectrophotometrically measured. In brief, monocytes at a density of $5 \times 10^{4}$ cells per well were seeded in into 96-well plates and treated with $\boldsymbol{f}$-MWCNT 5, $\boldsymbol{f}$-MWCNT 8, and $\boldsymbol{f}$-MWCNT 10 at $100 \mu \mathrm{g} \mathrm{mL}^{-1}$ for $24 \mathrm{~h}$ and $48 \mathrm{~h}$. The control group was treated with $\mathrm{Mg}^{2+} / \mathrm{Ca}^{2+}$-free-phosphate-buffered solution diluted in the culture medium at the same final concentration used for the MWCNT constructs. Then, the medium was removed and the cells were incubated with MTT $\left(0.5 \mathrm{mg} \mathrm{mL}^{-1}\right)$ for $4 \mathrm{~h}$ at $37^{\circ} \mathrm{C}$. Formazan crystals in the cells were solubilized with 100 $\mu \mathrm{L}$ of DMSO. The level of formazan in each well was determined by measuring its absorbance at $570 \mathrm{~nm}$. The cytotoxicity detection kit measures LDH activity released from damaged cells. The assay is performed in a 96-well microplate, according to the manufacturer's instructions. The supernatant of each sample was incubated with tetrazolium salt 2-( $p$-iodophenyl)-3-( $p$-nitrophenyl)-5-phenyl tetrazolium chloride (INT) to form colored formazan, a product which was quantitated colorimetrically.

\section{Caenorhabditis elegans assays}

The wild type Caenorhabditis elegans N2 and Escherichia coli OP50 strains (C. elegans food source) were used in this work according to standard protocol. ${ }^{27}$

Approximately 20 young adults hermaphrodites grown at $16{ }^{\circ} \mathrm{C}$, from a synchronized culture, were picked onto $3.5 \mathrm{~cm}$ - 
diameter NGM (Nematode growth media) plate contained OP50 E. coli. An aliquot $(100 \mu \mathrm{L})$ of $100 \mu \mathrm{g} \mathrm{mL} \mathrm{m}^{-1}$ nanotubes suspension, were added or not to the plates and the nematodes were incubated for several days at $16{ }^{\circ} \mathrm{C}$. Every day, animals were transferred to new plates and $100 \mu \mathrm{L}$ of nanotubes suspensions or PBS as a control were distributed on the NGM plates, before nematodes seeding. Worm death was scored by the absence of touch-provoked movement. We observed 60 worms at each time point and repeated the experiments three times.

After $24 \mathrm{~h}$ nanotubes-treatment, 1 day adult worms were allowed to lay eggs at $16{ }^{\circ} \mathrm{C}$ on NGM supplemented with $E$. coli OP50. Briefly, worms were transferred onto a new bacteria plate every day, and the number of newly hatched larvae was counted with a Zeiss Axiovert 25 microscope (Thornwood, NY). This was repeated for 4 days until the mother worms stopped laying eggs. Each day the progeny production was recorded and was compared with the untreated controls.

\section{Statistical analysis}

Experiments were performed at least in triplicate. Data are presented as mean $\pm \mathrm{SD}$, and Student's-test or one-way ANOVA analysis coupled with a Bonferroni post test (GraphPad Prism 4.0 software) was used to determine the statistical significance between experimental groups. Statistical significance was defined as $* p<0.05, * * p<0.01$, and ${ }^{* * *} p<0.001$.

\section{Results}

The aim of the present study is to evaluate the cellular internalization of multi-walled carbon nanotubes (MWCNTs) chemically conjugated or not with the peptide sequence previously demonstrated to suppress the defective growth phenotype due to mt tRNA mutations. Indeed studies on the yeast model have recently shown that overexpressed $\mathrm{mt}$ LeuRS-Cterm, $\beta 30 \_31$ and $\beta 32 \_33$ peptides (15 and 16 amino acids long, respectively) suppressed the respiratory defects due to mutations in mt tRNAs aminoacylated by class II, as well as class I mt
aaRS. ${ }^{5,12}$ The suppression capability of these plasmid constructs was also confirmed in human cells. ${ }^{10,11,13}$

We treated first WT yeast cells, with three different fluorescent-labelled MWCNTs (Fig. 1). The preparation of the CNT derivatives started with a first cycloaddition in presence of phthalimide protected amino acid and paraformaldehyde (Fig. 2), followed by a second one using a Boc-protected amino acid in order to have the orthogonal system $\boldsymbol{f}$-MWCNT 3 to work with. This derivative has been fully deprotected and conjugated with FITC, to obtain the reference compound f-MWCNT 5. In order to introduce the selected peptide, the phthalimide was removed to expose amine groups, exploited to link a maleimide residue ( $f$-MWCNT 7$)$. Derivative $f$-MWCNT 7 has been conjugated with the fluorescently labelled peptide ( $\boldsymbol{f}$-MWCNT 8) and with the non-labelled sequence. For the latter, FICT has been introduced in a following step ( $\boldsymbol{f}$-MWCNT 10).

\section{Yeast experiments}

We first studied cellular viability and toxicity; WT cells were inoculated in complete medium and grown overnight at $28^{\circ} \mathrm{C}$. Diluted culture $\left(10^{6}\right.$ cell per $\left.\mathrm{mL}\right)$ was exposed to increasing amount of MWCNTs (as described in Experimental section) from $2 \mathrm{~h}$ up to 8 days. The vitality of treated cells showed a behaviour similar to the control in all the concentrations and time points analyzed (data not shown). We further evaluated the internalization of MWCNTs and localization by fluorescence microscopy: cells were treated with different MWCNTs concentrations at different time of incubation to obtain a good fluorescence signal, distinct from the naïve unstained cell populations. Fig. 3 shows the fluorescent signal obtained after treatment of the WT yeast cells with two different concentrations of the three constructs $\left(10 \mu \mathrm{g} \mathrm{mL} L^{-1}\right.$ and $\left.40 \mu \mathrm{g} \mathrm{mL}^{-1}\right)$. In this case we observed that the best fluorescent signal into the cells was obtained incubating the culture for $40 \mathrm{~h}$. Fig. 3A shows that the cells treated with the f-MWCNT 5 (the vector control without the peptide sequence) have a diffused fluorescence, whereas in the same cells treated with the $\boldsymbol{f}$-MWCNT 8 or $\boldsymbol{f}$-MWCNT 10 separated fluorescent

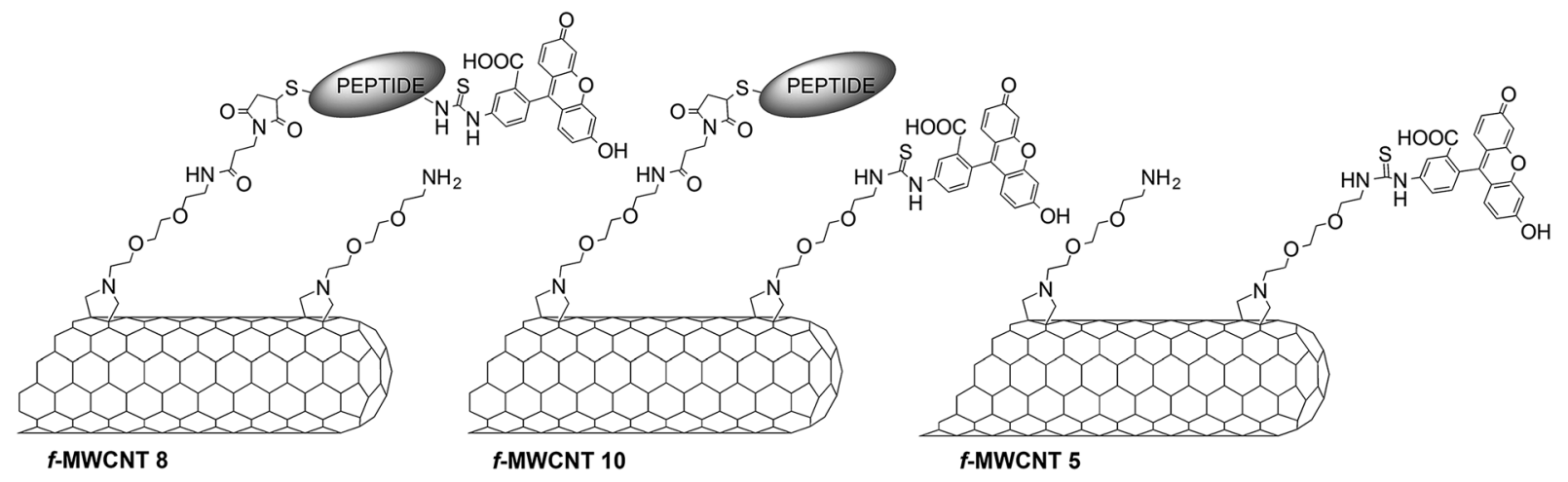

Fig. 1 Scheme of the three MWCNTs constructs described into this paper. $f$-MWCNT 8, $f$-MWCNT 10 and $f$-MWCNT 5, presenting respectively peptide and FITC bound to the same functional groups ( $f$-MWCNT 8 ), peptide and FITC bound to different groups of the tubes ( $f$-MWCNT 10$)$ and only the FITC ( $f$-MWCNT 5). 

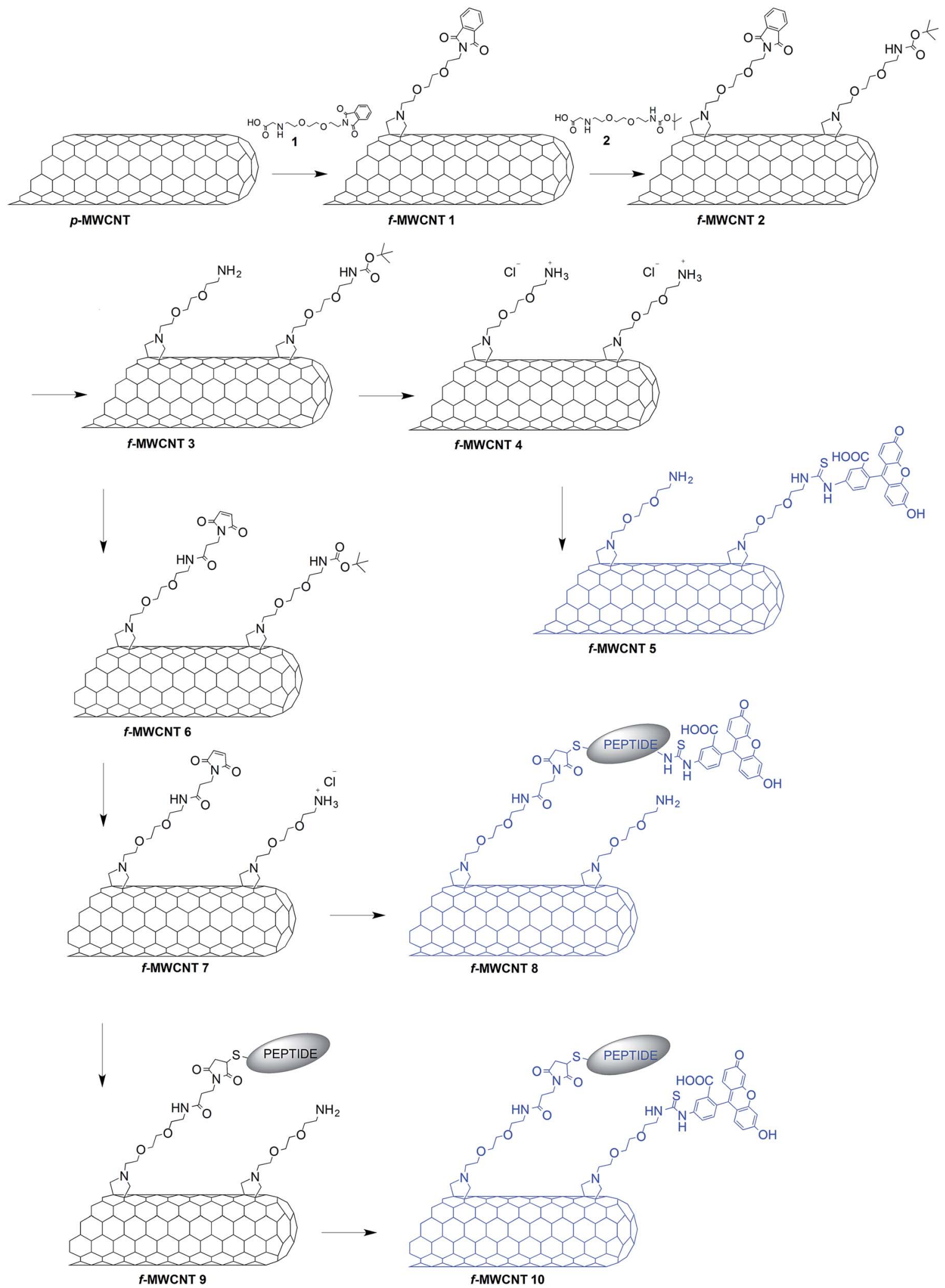

Fig. 2 Synthesis scheme of $f$-MWCNT 5, $f$-MWCNT 8 and $f$-MWCNT 10 (in blue colour).

dots appear (Fig. 3B and C). No considerable difference of the signal is observed using different amounts of the peptide conjugates.
Moreover, treatments with DAPI or MitoTracker Red and sequent co-localization of fluorescence show that $f$-MWCNT 8 and $f$-MWCNT 10 reached the mitochondria (Fig. 4A and B), 
A

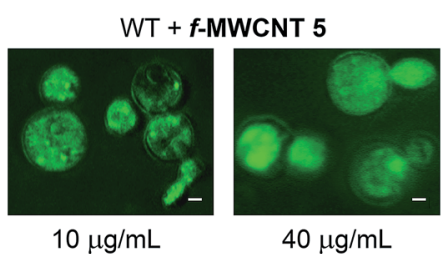

B

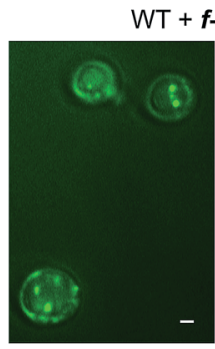

$10 \mu \mathrm{g} / \mathrm{mL}$

C

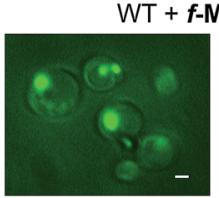

$10 \mu \mathrm{g} / \mathrm{mL}$

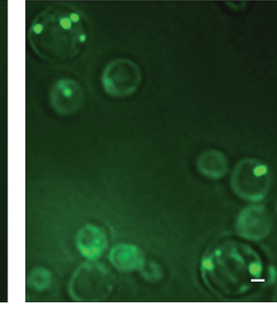

$40 \mu \mathrm{g} / \mathrm{mL}$

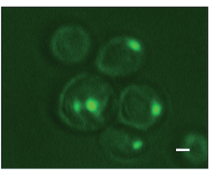

Fig. 3 Internalization of fluorescent signal of the MWCNTs constructs in S. cerevisiae. The WT yeast cells were incubated in YP liquid medium contained $2 \%$ of glucose at $28{ }^{\circ} \mathrm{C}$ with $10 \mu \mathrm{g} \mathrm{mL}^{-1}$ or $40 \mu \mathrm{g} \mathrm{mL}{ }^{-1}$ of $f$ MWCNT 5 (A), $f$-MWCNT 8 (B) or $f$-MWCNT 10 (C). After treating the cells were observed by fluorescence microscopy. Scale bar corresponds to $1 \mu \mathrm{m}$.

with best co-localization observed for the latter. This behaviour may be related with the different molecular structure of the constructs; in particular the $\boldsymbol{f}$-MWCNT 8 has FITC and peptide directly linked whereas in the $\boldsymbol{f}$-MWCNT 10 they are separated.
A

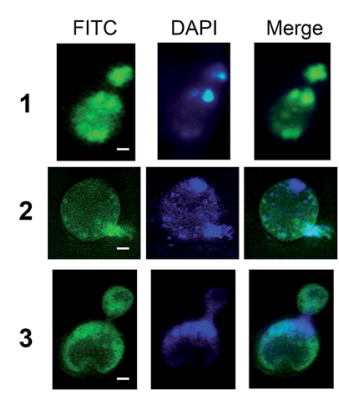

B

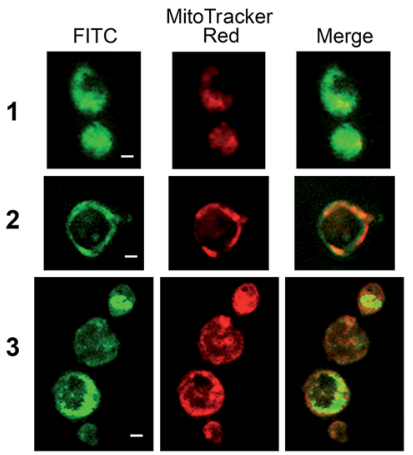

Fig. 4 Co-localization of fluorescent signals with mitochondria of $S$. cerevisiae. WT yeast cells were incubated in YP liquid medium contained $2 \%$ of glucose at $28^{\circ} \mathrm{C}$ with $20 \mu \mathrm{g} \mathrm{mL}{ }^{-1}$ of $f$-MWCNT 5 (lane 1 ), $f$-MWCNT 8 (lane 2) or $f$-MWCNT 10 (lane 3). Before fluorescence microscopy the same aliquot of each treated culture was stained with DAPI (A) or MitoTracker Red (B) to visualize the mitochondria. Scale bar corresponds to $1 \mu \mathrm{m}$.
The presence of the FITC on the peptide could in principle partially hinder the mitochondrial sequence, rendering the latter less prone to the recognition process. It is interesting to underline that, comparing the three pictures, the presence of $\boldsymbol{f}$ MWCNT 8 and $\boldsymbol{f}$-MWCNT 10, bearing the sequence peptide (lane 2 and 3, respectively), significantly induces an appreciable improvement of mitochondria localization; when the cells were incubated with the $\boldsymbol{f}$-MWCNT 5 the fluorescent signal diffusely appears (lane 1). This result confirms that the sequence of 332_33 peptide has an intrinsic mt targeting activity.

\section{Monocyte cytotoxicity assessment in vitro}

Human monocytes and macrophages are cells known to be involved in both the innate and adaptive immune responses, the role of which is equally fundamental in the initiation, maintenance and resolution of inflammatory processes. For this purpose, we tested circulating monocytes, because they represent the first line of defense in the immune response to foreign materials, including nanostructures in general. Thus they are of particular relevance in the investigation of the cell ability to internalize foreign body materials and of the toxic/ proinflammatory potential of the materials.

The in vitro viability of PBMCs (peripheral blood mononuclear cells) exposed to MWCNTs conjugates was tested by different approaches (Fig. 5): checking the release of the cytosolic enzyme lactate dehydrogenase (LDH) by using a LDH diagnostic kit; and the possible effect on the cell $\mathrm{mt}$ function by the MTT test. The measurement of LDH in the cell culture supernatants after $24 \mathrm{~h}$ and $48 \mathrm{~h}$ indicates no significant

\section{A}

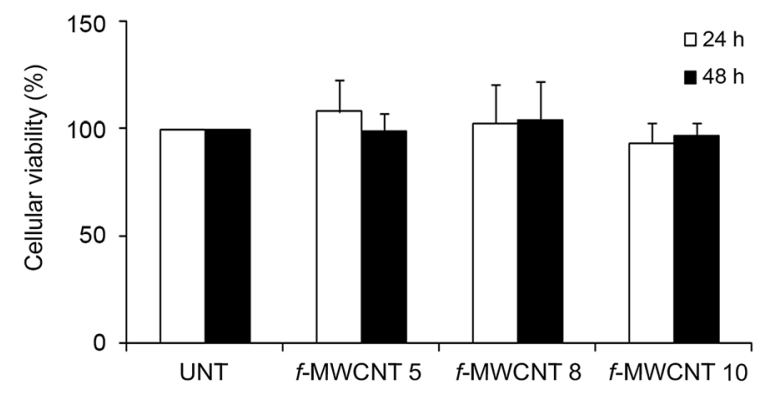

B

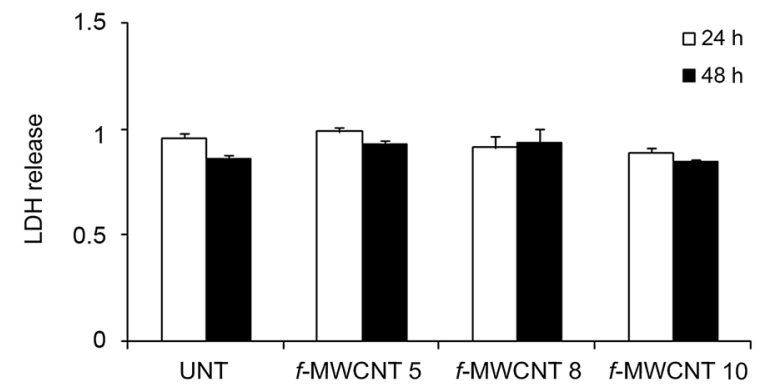

Fig. 5 Effect of the three MWCNTs constructs on human monocytes cell viability and $L D H$ release. Human monocytes were treated with $100 \mu \mathrm{g} \mathrm{mL}^{-1}$ of $f$-MWCNT 5, $f$-MWCNT 8 or $f$-MWCNT 10 for $24 \mathrm{~h}$ and $48 \mathrm{~h}$. The cell viability was assessed by MTT reduction assay (A) and $\mathrm{LDH}$ release assay (B). Values are expressed as mean \pm S.D. $(n=3)$. 
increase of LDH levels when the cells were exposed to $f$-MWCNT 5, $f$-MWCNT 8 and $f$-MWCNT 10, indicating a negligible cytotoxicity of these substrates on PBMCs (Fig. 5A). The MTT test further confirmed PBMC viability, showing that the conjugates do not affect cell mt function (Fig. 5B).

\section{Monocyte microscopy}

We further evaluated the internalization of fluorescentlylabelled MWCNTs and localization by fluorescence microscopy after $24 \mathrm{~h}, 48 \mathrm{~h}$ and $120 \mathrm{~h}$ of treatment with $100 \mu \mathrm{g} \mathrm{mL} \mathrm{m}^{-1}$ of constructs. Since the time of treatment did not change the fluorescence intensity, we showed a choice of pictures as example (Fig. 6). We observed that the PBMCs treated with the $f$ -

A

$24 \mathrm{~h}$

$48 \mathrm{~h}$

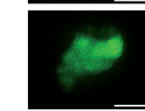

B

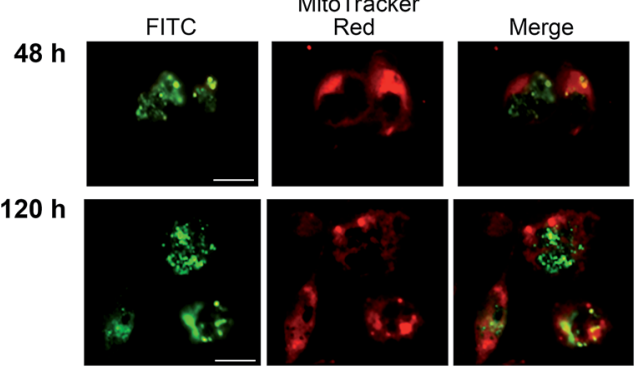

C

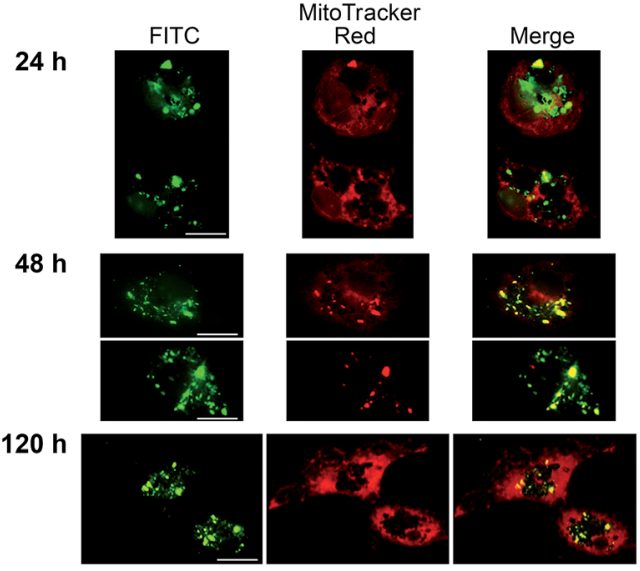

Fig. 6 Co-localization of fluorescent signals with mitochondria of human monocytes. Human monocytes were incubated with $100 \mu \mathrm{g}$ $\mathrm{mL}^{-1}$ of $f$-MWCNT 5 (A), $f$-MWCNT 8 (B) or $f$-MWCNT 10 (C) for $24 \mathrm{~h}$, $48 \mathrm{~h}$ and $120 \mathrm{~h}$. After treating the cells were stained with MitoTracker Red, fixed in $4 \%$ paraformaldehyde and observed by fluorescence microscopy. Scale bar corresponds to $10 \mu \mathrm{m}$.
MWCNT 5 (the vector control without the peptide sequence) for $24 \mathrm{~h}$ and $48 \mathrm{~h}$ have a diffused fluorescence (Fig. 6A), whereas in the same cells treated with $\boldsymbol{f}$-MWCNT 8 or $\boldsymbol{f}$-MWCNT 10 a separated fluorescent dots appear (Fig. 6B and C). After $24 \mathrm{~h}$ of treatment the MWCNTs were internalized; after $48 \mathrm{~h}$ and $120 \mathrm{~h}$ of incubation it was possible to find higher number of fluorescent nanotubes into the cells.

Treatment with MitoTracker Red and sequent co-localization of fluorescence shows that the best result is observed when the cells were incubated for longer times with MWCNTs (48 h and $120 \mathrm{~h}$ ). As previously observed for the yeast cells, the best colocalization between the mt signal and the MWCNTs is obtained when the peptide sequence is present, especially in the case of $\boldsymbol{f}$-MWCNT 10 construct (Fig. 6C). These results demonstrate that $\mathrm{mt}$ targeting activity of the $\beta 32 \_33$ peptide is optimized when this peptide is not bound to the FITC.

\section{Longevity and genotoxicity of Caenorhabditis elegans exposed to CNTs}

In order to evaluate the in vivo toxicity of these nanostructures, the nematode Caenorhabditis elegans, a well-established model system in nanotoxicology, was used. ${ }^{28}$ We first analyzed the effects of nanotubes on the worm longevity. A population of 1 day adult hermaphrodites was transferred on NGM E. coli OP50 plates on which $100 \mu \mathrm{L}$ of nanotube suspensions $\left(100 \mu \mathrm{g} \mathrm{mL} \mathrm{L}^{-1}\right)$

A

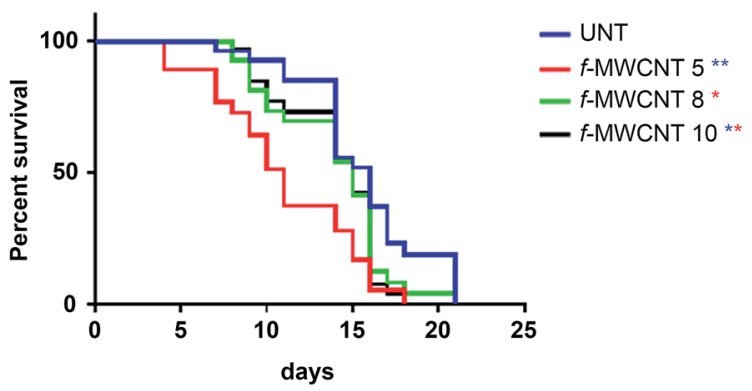

B

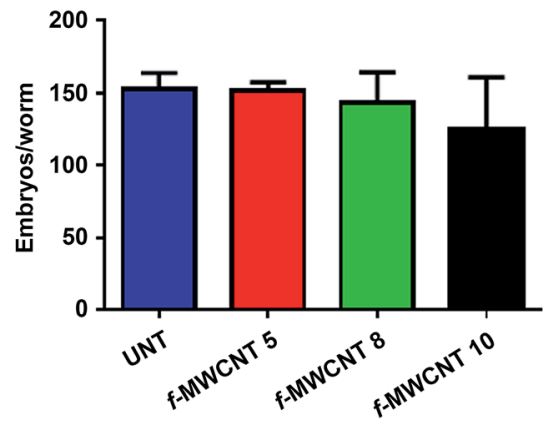

Fig. 7 Evaluation of MWCNTs toxicity in C. elegans: effect of nanotubes on nematode lifespan and fertility. (A) Kaplan-Meier survival plot of N2 worms untreated or treated with FITC-conjugated nanotubes with ( $f$-MWCNT 8 and $f$-MWCNT 10) or without (f-MWCNT 5) the peptide; $n=60$ for each data point of single experiments. (B) Average embryos production per worm in the presence of the three different nanomaterials. Untreated animals are reported as controls. Bars represent the mean of three independent experiments. 
was distributed, before nematodes seeding. Afterward, the viability was examined with respect to untreated animals (Fig. 7A). The life-span showed no significant differences between the worms treated with the two peptide-conjugated nanotubes ( $\boldsymbol{f}$-MWCNT 8 and $\boldsymbol{f}$-MWCNT 10) and the control, meanwhile the nanotube $\boldsymbol{f}$-MWCNT 5 induced a slight decrease in the survival.

To deeper investigate nanostructures bioassessment, we also analyzed C. elegans reproductive potential as an indicator of genotoxicity. Hence, a brood size assay for animals exposed every day to the nanotubes was performed. The progeny production of worms exposed to FITC-conjugated nanotubes with or without the peptide was almost identical to the untreated controls (Fig. 7B).

\section{Discussion}

Overexpression of the oligonucleotide sequences coding for the peptides $330 \_31$ (MAVLINNKACGKIPV) or $\beta 32 \_33$ (KKSFLSPRTALINFLV), comprised within the orthologous carboxy-terminal domain of human LeuRS, corrected the defects associated with several point mutations in yeast $\mathrm{mt}$ tRNA. ${ }^{5,12}$ This activity has been obtained also in transfected cybrid lines bearing substitution in $\mathrm{tRNA}^{\mathrm{Leu}(\mathrm{UUR})}$ and $\mathrm{tRNA}^{\mathrm{Lys}} .^{13}$

In view of potential therapeutic applications, a suitable carrier is necessary since peptides are unlikely to pass cell and mt membranes and to possess satisfactory bioavailability properties.

Nanotechnology based delivery vehicles provide numerous advantages to increase the therapeutic activities of small molecules, usually conferring them a better pharmacokinetics. Moreover, nanovehicles can be modified to target specific cells or organelles in order to carry the drug to the effective site of action. It is accepted that to deliver molecules inside the mt matrix and to have spatio-temporal control over drug release in different mt compartments, nanoparticles need to be engineered with precise size, lipophilic surface, appropriate charge, and specific targeting moieties on the surface. Moreover requirements of biocompatibility and biodegradability of the materials are necessary to envision potential in vivo uses of those platforms.

Currently described methods for mt gene therapy are allotropic genes, importable tRNAs, anti-genome agents, liposomes and ions, RNA transporters. ${ }^{29}$

The applicability of these interesting approaches in vivo remains to be determined and there are problems related to the uptake and localization of these artificial compounds, and evidence for functional delivery of DNA is lacking.

It should be noted that up to now none method has the demonstrated capability to cure mt diseases and successful gene replacement within mitochondria through homologous recombination has not been obtained yet. Therefore, non-viral vectors technique and new selective treatments to deliver molecules directly to mitochondria should be developed.

Several studies investigated the possibility of using mitochondria-targeted micelles, dendrimers and other materials. $^{\mathbf{3 0 , 3 1}}$ For example liposomes emerged as promising mitochondria delivery system in fact they were found to colocalize with MitoTracker Red in mitochondria, however size and polydispersity are the drawbacks of this technology. ${ }^{32}$

Among the numerous types of nanocarriers proposed since now, carbon nanotubes are emerging as possible delivery system.

Recently it has been reported that MWCNTs conjugated to a mitochondria targeting peptide sequence (KMSVLTPLLRGLTGSARRLPVPRAKC) exhibited high level of nanotube accumulation in mitochondria of macrophages and HeLa cells without showing any significant cytotoxicity. ${ }^{21}$

Our results indicate that the peptide sequence originally identified to have intrinsic mt targeting activity when overexpressed by plasmid in yeast and cybrid cells ${ }^{5,12,13}$ has similar property when conjugated to MWCNTs. In fact, $\boldsymbol{f}$-MWCNT 10 bearing peptide CKKSFLSPRTALINFLVK (Fig. 1), significantly improves the $\mathrm{mt}$ co-localization of FITC and $\mathrm{mt}$ fluorescence signals with respect to $\boldsymbol{f}$-MWCNT 8 and, especially, to $\boldsymbol{f}$-MWCNT 5 (Fig. 4 and 6). This improvement is highlighted by merged fluorescent dots, similarly to those previously observed for mitochondria-targeting MWCNT constructs. ${ }^{21,22}$

Moreover, we have demonstrated that the compounds here studied do not affect cellular viability and cytotoxicity both in vitro and in vivo also utilizing the simple pluricellular model $C$. elegans. Various special features such as its well characterized genome, genetic manipulability, easy of maintenance, short life cycle, transparent body with small size, etc. have led to an extensively use of the nematode to investigate the toxicity of nanomaterials. ${ }^{33,34}$ Moreover, many of the basic physiological processes and stress responses that are observed in higher organisms (e.g., humans) are conserved in C. elegans. Our data indicated that the all the analyzed constructs did not affect the life-span, the brood size and the reproductive potential of the nematodes although the FITC-conjugate ( $\boldsymbol{f}$-MWCNT 5) slightly decreased the survival of the animals (Fig. 7). It has been reported that MWCNTs exposure can produced damage in $C$. elegans on the functions of both primary and secondary targeted organs and that MWCNTs could be translocated into the secondary targeted organs such as reproductive organs. ${ }^{35,36}$ However, it should be taken into account the different size, shape, and surface functionality of the several MWCNTs tested, reflecting different degrees of toxicity.

Overall, $f$-MWCNT 10 can be considered a good nanoplatform for delivering of bioactive molecules and treating $\mathrm{mt}$ tRNAs deficiencies, although for its further development as drug delivery agent will be necessary to investigate the efficacy of the construct in cell lines bearing mt dysfunctions.

\section{Conflict of interest}

The authors have not conflict of interest to declare.

\section{Abbreviations}

$\begin{array}{ll}\mathrm{mt} & \text { Mitochondrial } \\ \mathrm{bp} & \text { Base-pair }\end{array}$




$\begin{array}{ll}\text { aa } & \text { Amino acids } \\ \text { aaRS } & \text { Aminoacyl-tRNA synthetase } \\ \text { CNTs } & \text { Carbon nanotubes } \\ \text { MWCNTs } & \text { Multi-walled carbon nanotubes } \\ \text { LDH } & \text { Lactate dehydrogenase } \\ \text { PBMCs } & \text { Peripheral blood mononuclear cells } \\ \text { LPS } & \text { Lipopolysaccharide } \\ \text { DAPI } & 4^{\prime} \text {,6-Diamidino-2-phenylindole } \\ \text { FITC } & \text { Fluorescein isothiocyanate }\end{array}$

\section{Acknowledgements}

All the authors gratefully acknowledge Prof. Laura Frontali for helpful discussions. This work was supported by Pasteur Institute - Cenci Bolognetti Foundation, and by Sapienza University of Rome (C26A144BN2), and by the European Union FP7 RADDEL program (ITN Marie Curie Actions PEOPLE-2011-290023).

\section{References}

1 C. De Luca, C. Besagni, L. Frontali, M. Bolotin-Fukuhara and S. Francisci, Gene, 2006, 377, 169.

2 C. De Luca, Y. Zhou, A. Montanari, V. Morea, R. Oliva, C. Besagni, M. Bolotin-Fukuhara, L. Frontali and S. Francisci, Mitochondrion, 2009, 9, 408.

3 A. Montanari, C. De Luca, L. Frontali and S. Francisci, Biochim. Biophys. Acta, 2010, 1803, 1050.

4 A. Montanari, C. De Luca, P. Di Micco, V. Morea, L. Frontali and S. Francisci, RNA, 2011, 17, 1983.

5 P. Di Micco, M. Fazzi D'Orsi, V. Morea, L. Frontali, S. Francisci and A. Montanari, Biochim. Biophys. Acta, 2014, 1843, 3065.

6 H. Park, E. Davison and M. King, RNA, 2008, 14, 2407.

7 J. Rorbach, A. A. Yusoff, H. Tuppen, D. P. Abg-Kamaludin, Z. M. Chrzanowska-Lightowlers, R. W. Taylor, D. M. Turnbull, R. McFarland and R. N. Lightowlers, Nucleic Acids Res., 2008, 36, 5787.

8 R. Li and M. X. Guan, Mol. Cell. Biol., 2010, 30, 2147.

9 E. Perli, C. Giordano, H. A. Tuppen, M. Montopoli, A. Montanari, M. Orlandi, A. Pisano, D. Catanzaro, L. Caparrotta, B. Musumeci, C. Autore, V. Morea, P. Di Micco, P. Gallo, S. Francisci, L. Frontali, R. W. Taylor and G. d'Amati, Hum. Mol. Genet., 2012, 21, 85.

10 H. T. Hornig-Do, A. Montanari, A. Rozanska, H. A. Tuppen, A. A. Almalki, D. P. Abg-Kamaludin, L. Frontali, S. Francisci, R. N. Lightowlers and Z. M. ChrzanowskaLightowlers, EMBO Mol. Med., 2014, 6, 183.

11 E. Perli, C. Giordano, A. Pisano, A. Montanari, A. F. Campese, A. Reyes, D. Ghezzi, A. Nasca, H. A. Tuppen, M. Orlandi, P. Di Micco, E. Poser, R. W. Taylor, G. Colotti, S. Francisci, V. Morea, L. Frontali, M. Zeviani and G. d'Amati, EMBO Mol. Med., 2014, 6, 169.

12 S. Francisci, A. Montanari, C. De Luca and L. Frontali, Mitochondrion, 2011, 11, 919.

13 E. Perli, A. Fiorillo, C. Giordano, A. Pisano, A. Montanari, P. Grazioli, A. F. Campese, P. Di Micco, H. A. Tuppen,
I. Genovese, E. Poser, C. Preziuso, R. W. Taylor, V. Morea, G. Colotti and G. d'Amati, Hum. Mol. Genet., 2016, 25, 903.

14 R. J. Koopmans and A. Aggeli, Curr. Opin. Microbiol., 2010, 13, 327.

15 S. Marrache, R. K. Pathak, K. L. Darley, J. H. Choi, D. Zaver,

N. Kolishetti and S. Dhar, Curr. Med. Chem., 2013, 20, 3500.

16 C. Ménard-Moyon, E. Venturelli, C. Fabbro, C. Samori, T. Da Ros, K. Kostarelos, M. Prato and A. Bianco, Expert Opin. Drug Discovery, 2010, 5, 691.

17 C. J. Serpell, K. G. Kostarelos and B. G. Davis, ACS Cent. Sci., 2016, 2, 190, review.

18 N. W. Shi Kam, T. C. Jessop, P. A. Wender and H. Dai, J. Am. Chem. Soc., 2004, 126, 6850.

19 K. Kostarelos, L. Lacerda, G. Pastorin, W. Wu, S. Wieckowski, J. Luangsivilay, S. Godefroy, D. Pantarotto, J. P. Briand, S. Muller, M. Prato and A. Bianco, Nat. Nanotechnol., 2007, 2, 108.

20 C. F. Lopez, S. O. Nielsen, P. B. Moore and M. L. Klein, Proc. Natl. Acad. Sci. U. S. A., 2004, 101, 4431.

21 A. Battigelli, J. Russier, E. Venturelli, C. Fabbro, V. Petronilli, P. Bernardi, T. Da Ros, M. Prato and A. Bianco, Nanoscale, 2013, 5, 9110.

22 S. L. Yoong, W. L. Lau, A. Y. Liu, D. Prendergast, H. K. Ho, V. C. Yu, C. Lee, W. H. Ang and G. Pastorin, Nanoscale, 2015, 7, 13907.

23 C. Monard-Moyon, C. Fabbro, M. Prato and A. Bianco, Chem.-Eur. J., 2011, 17, 3222.

24 G. Pastorin, W. Wu, S. Wieckowski, J. P. Briand, K. Kostarelos, M. Prato and A. Bianco, Chem. Commun., 2006, 11, 1182.

25 K. Kordatos, T. Da Ros, S. Bosi, E. Vazquez, M. Bergamin, C. Cusan, F. Pellarini, V. Tomberli, B. Baiti, D. Pantarotto, V. Georgakilas, G. Spalluto and M. Prato, J. Org. Chem., 2001, 66, 4915.

26 B. J. Thomas and R. Rothstein, Genetics, 1989, 123, 725.

27 S. Brenner, Genetics, 1974, 77, 71.

28 R. D. Handy, G. Cornelis, T. Fernandes, O. Tsyusko, A. Decho, T. Sabo-Attwood, C. Metcalfe, J. A. Steevens, S. J. Klaine, A. A. Koelmans and N. Horne, Environ. Toxicol. Chem., 2012, 31, 15.

29 S. Adhya, B. Mahato, S. Jash, S. Koley, G. Dhar and T. Chowdhury, Mitochondrion, 2011, 11, 839, review.

30 R. K. Pathak, N. Kolishetti and S. Dhar, Wiley Interdiscip. Rev.: Nanomed. Nanobiotechnol., 2015, 7, 315, review.

31 R. Wen, B. Banik, R. K. Pathak, A. Kumar, N. Kolishetti and S. Dhar, Adv. Drug Delivery Rev., 2016, 99, 52, review.

32 C. Salvador-Morales, L. Zhang, R. Langer and O. C. Farokhzad, Biomaterials, 2009, 30, 2231.

33 J. Choi, O. V. Tsyusko, J. M. Unrine, N. Chatterjee, J. M. Ahn, X. Yang, B. Lila Thornton, I. T. Ryde, D. Starnes and J. N. Meyer, Environ. Chem., 2014, 11, 227.

34 S. K. Jung, X. Qu, B. Aleman-Meza, T. Wang, C. Riepe, Z. Liu, Q. Li and W. Zhong, Environ. Sci. Technol., 2015, 49, 2477.

35 Q. Wu, Y. Li, Y. Li, Y. Zhao, L. Ge, H. Wang and D. Wang, Nanoscale, 2013, 5, 11166.

36 A. Nouara, Q. Wu, Y. Li, M. Tang, H. Wang, Y. Zhao and D. Wang, Nanoscale, 2013, 5, 6088. 